Bol. Acad. peru. leng. 63. 2018 (243-253)

\title{
LOS ARCAÍSMOS EN LOS CUENTOS CRIOLLOS DE ABRAHAM VALDELOMAR
}

\author{
Cynthia Briceño Valiente \\ Universidad de Piura
}

Fecha de recepción:

$10 / 03 / 2018$

Fecha de aceptación:

$31 / 05 / 2018$

Pedro Abraham Valdelomar Pinto es considerado uno de los mejores cuentistas peruanos, pues si bien cultivó con esmero todos los géneros, es en la narrativa donde se destaca. Sobre su talento, Ricardo SilvaSantisteban (Valdelomar, 2001: I.22) indica: «Valdelomar es lo que se llama un narrador nato y, en mi concepto, no solo es el verdadero creador del cuento peruano y el más destacado de los escritores, sino también uno de los más grandes cuentistas del país (sino el más grande e importante) sobre todo por el aire de originalidad que se respira en sus cuentos, su variedad, su habilidad para la conducción de los eventos narrativos y las excelencias de su estilo».

El extraordinario ingenio de Valdelomar lo lleva a crear una variedad de relatos cortos agrupados con los títulos de Cuentos yanquis,

https://doi.org/10.46744/bapl.201801.011 
https://doi.org/10.46744/bapl.201801.011

Cuentos criollos, Cuentos chinos y Cuentos fantásticos ${ }^{1}$. No obstante, la excelencia narrativa de Abraham Valdelomar se manifiesta en sus Cuentos criollos. Estos se distinguen no solo por expresar una gran sensibilidad universal y panteísta, sino también por mostrar la extraordinaria riqueza alegórica con la que se representan las costumbres de provincia y el modo de vida costeño. Los cuentos criollos como «El Caballero Carmelo», «Los ojos de Judas», «El buque negro», «La paraca», "Hebaristo el sauce que murió de amor», «El vuelo de los cóndores» y «Yerba santa», constituyen la especial atención de Valdelomar hacia el auténtico mundo de su infancia en su tierra natal y en el puerto de Pisco. El ser reconocido como el iniciador del cuento criollo, y que sus relatos sean lo más estimable y trascendental de su narrativa, no es solo el resultado de la crítica de los literatos y del aprecio de los lectores; sino, también, de la valoración que el mismo Valdelomar hiciera de su obra: «El criollismo entre nosotros, el noble criollismo, la gentil literatura del terruño comienza, si no me equivoco, con el cuento "El caballero Carmelo"» (Valdelomar, citado por Sánchez, 1969: 234).

El criollismo literario -corriente artística que nace en Hispanoamérica a finales del siglo xix y que alcanza las tres primeras décadas del siglo xx- buscaba, a través de la prosa, transmitir el sentimiento de lo vernáculo, retratar las costumbres, las creencias y las formas de vida de los pueblos ${ }^{2}$, y elevar el nivel artístico de la literatura. Es así que «en los años veinte prosperaron relatos basados en la vida y en los tipos regionales» (Rita Gnutzmann, 2007: 38).

El criollismo, como movimiento literario hispanoamericano, tiene como principal propósito la consolidación de la cultura hispanoamericana y la declaración de su oposición a la cultura europea o extranjera. Abraham Valdelomar, aunque tomó una postura esnob

1 Estas agrupaciones de los cuentos de Valdelomar aparecen en Abrabam Valdelomar, Obras completas II (2001), libro editado y prologado por Ricardo Silva Santisteban.

2 Se entiende por pueblo a la comunidad rural que conservaría la esencia de la nación, en contraste con la modernidad y el cosmopolitismo capitalinos. Es así que el ingrediente nacionalista y tradicionalista suele ser relevante. 
https://doi.org/10.46744/bapl.201801.011

con una particular imagen de flâneur, manifestada desde el aristocrático seudónimo de «el Conde de Lemos» logró reflejar en sus cuentos el sentimiento criollo mediante una descripción minuciosa y tierna del paisaje aldeano, de la vida sencilla cerca al mar y de la generosidad de la tierra provinciana. Sobre el entrañable relato de «El caballero Carmelo», Augusto Tamayo Vargas (1992: 700) vierte una apreciación especial: «El provincialismo campesino, la ternura familiar, el sentimiento del cosmos reflejado en personas y cosas y, especialmente, en el mar: todo está presente en ese cuento».

La prosa ingeniosa de Valdelomar logra reflejar el espíritu criollo y regionalista que conservan sus relatos; no obstante, la presencia de arcaísmos o expresiones de un español castizo pone en tela de juicio dicha afirmación y, en consecuencia, nos invita a preguntarnos: ¿El uso de los recursos lingüísticos conocidos como arcaísmos en los Cuentos criollos de Valdelomar buscan reforzar la sensación de criollismo o crear distancia con ella? Para dar respuesta a la inquietud, primero empezaremos revisando el sentido de arcaísmo y su trascendencia en el contexto literario.

Se denomina arcaísmo toda voz o construcción que se considera anticuada respecto de una época determinada; en otras palabras, el arcaísmo es un componente lingüístico que, si bien ha sido empleado ampliamente en el pasado, ha caído en desuso. Mónica Strömberg (2002: 185) llega a la conclusión de que si un elemento lingüístico ha quedado en desuso en el español peninsular, pero se emplea en la mayoría de las normas hispanoamericanas, especialmente en las de mayor reconocimiento cultural, vendría a ser un falso arcaísmo o un arcaísmo parcial, puesto que lo sería solo en comparación con el español de la península. En cambio, si una forma lingüística se emplea solo en algunas normas de algunos territorios hispanoamericanos y estas áreas idiomáticas son poco importantes — como el castellano de las poblaciones rurales-, viene a constituirse en un auténtico arcaísmo. Isaías Lerner (citado por Strömberg, 2002: 188) reconoce como arcaísmos las voces que han dejado de usarse en el castellano general de América y España, pero que permanecen en la norma 
https://doi.org/10.46744/bapl.201801.011

popular y rural de América. Baldonado (Ibid., p. 189) advierte que la noción común de arcaísmo tiene en cuenta las palabras que han perdido vigencia en el castellano general, pero que son empleadas ocasionalmente por algunos autores para enriquecer el léxico literario. En ese sentido, la postura de Mónica Strömberg (2002: 189) considera dos tipos de arcaísmos: «En un primer plano, arcaísmo significa el uso no deliberado de una palabra que generalmente ha caído en desuso (en una norma particular de la lengua en cuestión). Esto da lugar, en un segundo plano, al uso deliberado de un arcaísmo —un arcaísmo literario».

Como arcaísmos arraigados en el uso literario - lo cual constituye también una evidencia de la condición conservadora del español de América-, Lope Blanch (1968: 94) establece una serie de voces y construcciones que corresponden con el español de los siglos XVI y XVII. En primer lugar, menciona el uso de la forma verbal del pretérito imperfecto del subjuntivo — como cantara, soñara- con valor de pluscuamperfecto de indicativo (babía cantado, había soñado). Para citar un ejemplo, en el siguiente fragmento de «El Caballero Carmelo» (Valdelomar, 2001: II.136) aparece la forma acaeciera en lugar de había acaecido: "Así entró en nuestra casa este amigo íntimo de nuestra infancia ya pasada, a quien acaeciera digna historia de relato, cuya memoria perdura aún en nuestro hogar como una sombra alada y triste: el Caballero Carmelo».

En cuanto a las formas no verbales, en el siguiente texto se aprecia un caso complejo del participio: «El cabrito era un bello animal, de suave piel, alegre, simpático, inquieto, cuyos cuernos apenas apuntaban; además, no estaba comprobado que hubiera muerto al pollo». Nótese que en esta última expresión «hubiera muerto», en lugar del participio de matar (matado) se ha empleado el participio de morir (muerto). Aquí el participio muerto — que aparece con el sentido de 'matar' —, corresponde a un uso causativo antiguo, normal en épocas pasadas, el mismo que aparece en el Quijote (Diccionario panbispánico de dudas, 2005): «iCiérrese la puerta de la venta! iMiren que no se vaya nadie, que han muerto aquí un hombre!» (Cervantes, 1846: 258). 
https://doi.org/10.46744/bapl.201801.011

En segundo lugar, Lope Blanch (1968: 94) señala —como muestra evidente del arcaísmo americano- el empleo de palabras en desuso. Dentro de las voces que se recogen en los cuentos de Valdelomar tenemos luengos (con el significado de 'largos, prolongados'), aquestos (con la misma función de 'estos') y maguer (con el mismo sentido de 'aunque'). En el siguiente fragmento de "Yerba Santa» (Valdelomar, 2001: II.183) apreciamos el uso de uno de los términos mencionados: «Los ricos hombres de Cañete solían llevar, en persona, haciendo luengas caminatas, el presente de sus corazones agradecidos al señor». En el texto de Cervantes y en Lazarillo de Tormes las voces señaladas son empleadas con frecuencia: «Y, lo primero que hizo fue limpiar unas armas que habían sido de sus bisabuelos, que — tomadas de orín y llenas de moho- luengos siglos había que estaban puestas y olvidadas en un rincón» (Cervantes, 2008: 31).

Otros arcaísmos que caracterizan el lenguaje de los textos criollos de Valdelomar son los relacionados con la morfología y la sintaxis. Con respecto a la primera, aparecen las formas dello, della y sus respectivos plurales, resultado de la contracción de la preposición de más el pronombre personal y del neutro ella, ello. Aquí un fragmento de «Yerba Santa» (Valdelomar, 2001: II.187): «Ya por la tarde, bajado un poco el sol, tomamos nuevamente las bestias para ir a la hacienda, cuyo nombre ahora no recuerdo, que tantos años dello hace y no me recuerdo tampoco qué camino hicimos para llegar. Solo está fija en mi memoria la visión de esa rara hacienda. Era fresca y fecunda la tierra [...]». Las contracciones señaladas también se recogen en los textos clásicos antiguos como, por ejemplo, en Lazarillo de Tormes (2006: 120): "De esta manera, estuve con mi tercer y pobre amo, que fue este escudero [...], desde el primer día que con él asenté, le conoscí ser estranjero, por el poco conoscimiento y trato que con los naturales della tenía».

En el plano de la sintaxis, los pronombres personales átonos (me, te, se, lo, las, etc.) aparecen inevitablemente después del verbo, lo que gramaticalmente conocemos como verbos con pronombres enclíticos. Aquí un fragmento de «El Caballero Carmelo» (Valdelomar, 
2001: II.142): «Lanzáronlos al ruedo con singular ademán. Brillaron las cuchillas, miráronse fijamente; alargaron los cuellos, erizadas las plumas, y se acometieron». Estas formas o verbos con pronombres enclíticos abundan también en los textos clásicos, como en la obra Don Quijote de la Mancha (Cervantes, 2008: 316): «Habíase en ese tiempo vestido Cardenio los vestidos que Dorotea traía cuando la hallaron que, aunque no eran muy buenos, hacía mucha ventaja a los que dejaba. Apeáronse junto a la fuente, y con lo que el cura se acomodó en la venta satisficieron, aunque poco, la mucha hambre que todos traían».

Otro recurso sintáctico que se emplea en obras del siglo XVI, como en La Araucana, es el verbo haber en lugar de tener, es decir, con uso posesivo: «Los juegos y ejercicios acabados, / para el valle de Arauco caminaron, / do a las usadas fiestas los soldados / de toda la provincia convocaron, / fueron bastantes plazos señalados, / joyas de gran valor se pregonaron, / de los que en ella fuesen vencedores, / premios dignos de haber competidores» (Ercilla, 2002: 315). Resulta interesante comprobar, sin embargo, que el uso del verbo haber con el sentido de tener, también, está presente en la prosa de los cuentos criollos de Valdelomar (2001), como en «Hebaristo el sauce que murió de amor» y en «El Caballero Carmelo»: «Debía llamarse Hebaristo y tener treinta años, porque había el mismo aspecto cansino y pesimista, la misma catadura enfadosa y acre del joven farmacéutico» (p. 200, II); «Iglesia ni cura babían, en mi tiempo, las gentes de San Andrés. Los domingos, al clarear el alba, iban al puerto con los jumentos cargados de corvinas frescas y luego en la capilla, cumplían con Dios» (p. 140, II).

Con respecto a las preposiciones, es frecuente el uso de las partículas en y de en construcciones que, actualmente, no se consideran correctas, como en placía de sembrar (en lugar de le placía sembrar), en oyéndolo (en lugar de oyéndolo) o en todo era en silencio (en lugar de todo estaba en silencio). Una de ellas aparece, por ejemplo, en «El buque negro»: "Anfiloquio placía de sembrar maíz que, una vez cosechado, él mismo comíase, y a mí y a Jesús, mi hermana menor, nos encantaban las violetas y una higuera apenas crecida. Así, mis padres nos enseñaron a sembrar la tierra [...]» (Valdelomar, 2001: II.170). 
https://doi.org/10.46744/bapl.201801.011

En los cuentos criollos «La Paraca» y «Los ojos de Judas», se observa un uso frecuente de expresiones como el volar de las velas, cada silbar del viento o se oía el chocar, en las que los infinitivos se emplean en función sustantiva: «Sacan sus botes sobre la arena de la orilla, y alineados esperan que pase el viento, y si hay algunos en el mar, los parientes y amigos aguardan inquietos el retorno, las viejas rezan, y los muchachos abren tremendos ojos buscando en el horizonte el volar de las velas triangulares y blancas como alas [...]. Cada chasquear de las olas, cada silbar del viento les parecía un sonar de quilla o un crujir de vela. Al calor de una fogata, sentados viejos y viejas, muchachos de espantados ojos y mozas que lloraban, pasaron algunas horas más» (Ibid., p. 196-197). "Así, a medida que el carro avanzaba, las luces iban quedando inmóviles en el espacio como estrellas sangrientas, y al final iba disminuyendo su brillor y dejando sus luces a lo largo del muelle como una familia cuyos miembros fueron muriendo sucesivamente de una enfermedad [...]. Solo se oía el chocar de los cubiertos con los platos o los pasos apagados de la sirvienta $[\ldots]$ » (Ibid., p.159).

Ya analizados los arcaísmos en los cuentos de Abraham Valdelomar, se puede afirmar que estos corresponden con el lenguaje literario de los siglos XVI y XVII. Con respecto a la lengua conservadora de América, Lope Blanch (1968: 91) considera un error creer que esta derive de la lengua que nos trajeron los compañeros de Colón en 1492; asimismo, el autor es enfático y menciona: «aun circunscribiéndonos a la época inicial de las conquistas, habremos de convenir en que el español de los soldados y navegantes no correspondía ya, en el terreno del habla, al idioma literario de Juan de Mena ni al codificado por Nebrija en su Gramática de 1492, sino al plenamente renacentista de Garcilaso y Boscán [...], o —si siguiéramos la costumbre de relacionarlos con la lengua literaria- al del Lazarillo de Tormes y de La Araucana de Ercilla $[\ldots] »^{3}$.

3 El castellano de América fue desde sus comienzos el castellano moderno y no el medieval. Es decir, la misma lengua viva hablada en España, a la que se acercaron los autores renacentistas en contraste con el artificio de la literatura cortesana anterior al siglo Xvi. 
https://doi.org/10.46744/bapl.201801.011

Por otro lado, y teniendo en cuenta que los arcaísmos están relacionados con el contexto rural, el manejo cuidadoso y acertado de los mismos en los Cuentos criollos logra estimar la lengua del campesino, del pescador, del provinciano, $\mathrm{y}$ - al mismo tiempo- consiguen alejarse del lenguaje pintoresco — propio del costumbrismo - con lo cual el escritor estaría buscando crear distancia. Como sostiene también Lope Blanch (1968: 96), los arcaísmos difícilmente pretenden conservar el uso antiguo de un idioma, sino más bien buscan que el lenguaje literario se encargue de elevar el carácter estilístico de una lengua.

Los arcaísmos de los relatos de Valdelomar, al evocar el lenguaje castellano de los clásicos del Siglo de Oro, refuerzan la continuidad racial entre los conquistadores y los criollos del siglo xix. En otras palabras, acentúan el sentimiento nacionalista criollo, en cuanto que buscaba mediante él revalorizar los conceptos de mestizaje e hispanidad. En relación con el lenguaje evocador, Armando Zubizarreta (Valdelomar, 1973: 5) señala: «En la historia de un gallo de corral familiar que es El caballero Carmelo, la figura y la hazaña del ambiente logran los perfiles de una hermosa imagen plástica gracias al empleo de un lenguaje refinado y a una sabia utilización de la retórica cervantina de libros de caballería». En ese sentido, los arcaísmos se enlazan con la ternura y el tono coloquial de la narración recreando una práctica traída a América por los conquistadores y ahora costumbre criolla: la pelea de gallos, y mostrando, al mismo tiempo, pasajes de la vida en familia, y costumbres típicas del ambiente rural y costeño.

En el contexto de la narrativa, en especial en el del cuento, el modernismo tuvo un mayor arraigo y se manifestó de forma extraordinaria. Como modernista, Valdelomar buscaba la elegancia, el refinamiento y la sonoridad en la expresión, lo que lo lleva a esmerarse en la elección del léxico y en la formación de estructuras lingüísticas, sin descuidar la sencillez en la expresión de los sentimientos íntimos. Por lo tanto, los arcaísmos en los cuentos criollos constituyen un modo particular de corresponder con la presunción culturalista del modernismo. A Jiménez y a Morales (1998: 29) no les cabe duda de que 
https://doi.org/10.46744/bapl.201801.011

existe un esteticismo que se extralimita, una vocación de aristocratismo en el lenguaje y una intencionalidad cosmopolita y exótica en el quehacer literario de los modernistas.

Finalmente, se puede afirmar que los arcaísmos de los cuentos, además de reforzar la sensación de criollismo, se suman al castellano de la época para intensificar el color de las descripciones de la vida en provincia y de los magníficos paisajes que nos ofrece la naturaleza costeña: todo ello se unifica magistralmente en el cuento criollo de Valdelomar, ofreciéndonos un relato renovador, entrañable y genuino. 
https://doi.org/10.46744/bapl.201801.011

\section{BIBLIOGRAFÍA}

ANÓNIMO (2006). Lazarillo de Tormes. Madrid: Espasa Calpe.

CERVANTES, M. de (2008). Don Quijote de la Mancha. Lima: Santillana.

. (1846). Don Quijote de la Mancha. Madrid: Biblioteca de autores españoles. Recuperado de https://books.google. com.pe/books?id $=$ 2oqdhqCSk5AC.

ERCILlA, A. (2002). La Araucana. Madrid: Cátedra.

GNUTZMANN, R. (2007). Novela y cuento del siglo XX en el Perú. Alicante: Cuadernos de América sin nombre.

JIMÉNEZ, J. y MORALES, C. (1998). Laprosa modernista hispanoamericana. Madrid: Alianza Editorial.

LOPE BLANCH, J. M. (1968). El supuesto arcaísmo del español americano. Anuario de Letras. Lingüística y Filosofía, 7, 85-109.

REAL ACADEMIA ESPAÑOLA (2005). Diccionario panhispánico de dudas. Madrid: Santillana.

SÁNCHEZ, L. (1969). Valdelomar o la belle époque. México: Fondo de Cultura Económica.

STRÖMBERG, M. (2002). Arcaísmo como concepto. Romansk Forum, 2 (16), 183-183.

TAMAYO V., A. (1992). Literatura peruana. Lima: PEISA.

VALDELOMAR, A. (1973). Cuentos. Lima: Universo S. A. . (2001). Abraham Valdelomar, Obras completas I. Lima: Ediciones COPÉ. 
https://doi.org/10.46744/bapl.201801.011

. (2001). Abraham Valdelomar, Obras completas II. Lima: Ediciones COPÉ. 